Res., Soc. Dev. 2019; 8(1):e581510

ISSN 2525-3409 | DOI: http://dx.doi.org/10.33448/rsd-v8i1.510

\title{
Formação de Recursos Humanos na Captação de Órgãos para Transplantes: Ensino à Distância (EaD)
}

\section{Human Resources Training For Organ Procurement in Transplantations: Distance Learning \\ Formación de Recursos Humanos en la Captación de Órganos para Trasplantes: Enseñanza a Distancia (EaD)}

Simone Lysakowski

ORCID: https://orcid.org/0000-0003-3959-956X

Santa Casa de Misericórdia de Porto Alegre (ISCMPA), Brasil

E-mail: silysa@gmail.com

Rita Catalina Aquino Caregnato

ORCID: https://orcid.org/0000-0001-7929-7676

Universidade Federal de Ciências da Saúde de Porto Alegre (UFCSPA), Brasil

E-mail: ritac.ufcspa@gmail.com

Aline Winter Sudbrack

ORCID: https://orcid.org/0000-0002-8972-7737

Universidade Federal de Ciências da Saúde de Porto Alegre (UFCSPA), Brasil

E-mail: alinewin.ufcspa@gmail.com

Recebido: 11/07/2018 - Aceito: 20/08/2018

\section{Resumo}

O transplante é a única alternativa terapêutica para o tratamento de algumas doenças e, em muitos casos, a esperança de vida para inúmeros pacientes que aguardam em lista. No Brasil, a porcentagem de famílias que recusam a doação de órgãos de seus familiares é alta, e por isso é necessário ter profissionais de saúde capacitados para atuarem junto ás famílias no processo de doação. O objetivo deste estudo foi desenvolver e aplicar um curso de ensino à distância $(\mathrm{EaD})$ sobre doação e transplante de órgãos, visando qualificar e capacitar médicos e enfermeiros de Unidades de Terapia Intensivas e Emergências do Rio Grande do Sul. Trata-se de uma intervenção educativa de abordagem mista, com a participação de 30 profissionais. Os resultados evidenciam que o curso permitiu beneficiar os profissionais de diversas regiões do Estado, capacitando para atuação no processo de doação de órgãos e transplantes. Este foi considerado importante para a reflexão do fazer e aprimoramento das ações frente á doação e 
transplantes, oportunizando o aperfeiçoamento dos profissionais que não teriam oportunidade de deslocamento aos grandes centros. O modelo de $\mathrm{EaD}$ foi desenvolvido por especialistas nos assuntos, oferecendo material atualizado e facilitando a realização do curso, que foi avaliado como positivo por todos os participantes.

Palavras-chave: Educação a Distância; Educação Continuada; Educação em Saúde; Obtenção de Tecidos e Órgãos; Transplante de Órgãos.

\section{Abstract}

Transplantation is the only treatment for some diseases, and in many cases, it represents the hope of living for patients in waiting lists. In Brazil, the percentage of families that refuse to donate their relatives' organs is still high. Therefore, health professionals prepared to work with those families during the donation process are required. The goal of this study was to develop and organize a distance learning course about organ donation and transplantation. It aimed at qualifying and preparing doctors and nurses in Emergency and Intensive Care Units in the State of Rio Grande do Sul. The course's activities had a blended learning approach, and 30 professionals participated in it. Results show that the course benefited professionals from different regions in the State. It prepared them to work in the organ donation and transplantation process. This was deemed relevant because participants were able to reflect on their donation and transplantation actions and improve them. The course allowed training of professionals who could not travel to large urban centers. The distance learning model was developed by specialists and offered updated material, which made taking the course easier and was a positive aspect according to all participants.

Keywords: Distance Learning; Continuing Education; Health Education; Tissue and Organ Procurement; Organ Transplantation

\section{Resumen}

El trasplante es la única alternativa terapéutica para el tratamiento de algunas enfermedades y, en muchos casos, la esperanza de vida para muchos pacientes que esperan en lista. En Brasil, el porcentaje de familias que rechazan la donación de órganos de sus familiares es alta, y por eso es necesario tener profesionales de salud capacitados para actuar junto a las familias en el proceso de donación. El objetivo de este estudio fue desarrollar y aplicar un curso de enseñanza a distancia $(\mathrm{EaD})$ sobre donación y trasplante de órganos, buscando calificar y capacitar médicos y enfermeros de Unidades de Terapia Intensiva y Emergencias de Rio Grande do Sul. Se trata de una intervención educativa de enfoque mixto, con la participación 
de 30 profesionales. Los resultados evidencian que el curso permitió beneficiar a los profesionales de diversas regiones del Estado, capacitando para actuación en el proceso de donación de órganos y trasplantes. Este fue considerado importante para la reflexión del hacer y perfeccionamiento de las acciones frente a la donación y trasplantes, oportunizando el perfeccionamiento de los profesionales que no tendrían oportunidad de desplazamiento a los grandes centros. El modelo de $\mathrm{EaD}$ fue desarrollado por especialistas en los temas, ofreciendo material actualizado y facilitando la realización del curso, que fue evaluado como positivo por todos los participantes.

Palabras clave: Educación a Distancia; Educación contínua; Educación en Salud; Obtención de Tejidos y Órganos; Trasplante de Órganos.

\section{Introdução}

Atualmente o transplante é uma das únicas alternativas terapêuticas para o tratamento de algumas doenças, sendo significativamente eficaz na melhoria da qualidade de vida dos pacientes e no funcionamento físico e psicossocial (PEREIRA, FERNANDES, SOLER, 2009; KAZLEY, et al., 2012). Entretanto, este não é realizado se não houver um doador e, neste complexo processo, observa-se o aumento no número de pacientes ativos inscritos no cadastro técnico nacional brasileiro e a baixa oferta de órgãos (PESSOA, SCHIRMER, ROZA, 2013).

A crescente desproporção entre o número de pacientes em lista de espera por transplantes e doadores, revela alguns pontos a serem trabalhados, como: a não notificação de pacientes em Morte Encefálica (ME) às Centrais de Transplantes Estaduais; a falta de políticas de educação aos profissionais de saúde referentes ao processo de doação e transplantes; e a recusa familiar para a doação (PEREIRA, FERNANDES, SOLER, 2009).

O último Registro Brasileiro de Transplantes (RBT), referente ao ano de 2017, aponta o aumento no número de doações e transplantes em todo o Brasil, situação essa diferente em 2015, período de realização do curso, quando indicava uma pequena queda no número de doadores de múltiplos órgãos, comparado ao ano anterior. Porém, a recusa familiar para a doação de órgãos no país se mantém elevada, apresentando $42 \%$ de negativa (RBT, 2017).

Em 2008, ao serem pesquisados médicos intensivistas na capital do Rio Grande do Sul (RS), encontrou-se um prevalência de $17 \%$ de desconhecimento do conceito de ME, $20 \%$ de incompreensão quanto à necessidade legal do exame complementar para o diagnóstico e $29 \%$ não souberam o horário legal para o óbito dos pacientes em ME, ficando evidente que naquela época havia deficiência de conhecimento por parte desses profissionais que, com 
maior frequência, se defrontam com os pacientes em ME (SCHEIN et al., 2008). Outro estudo apontou que $61,9 \%$ dos intensivistas, participantes da pesquisa, informaram não terem recebido treinamento sobre as condutas para manutenção dos órgãos (SILVA et al., 2018). Estudos mais recentes apontam o conhecimento frente ao assunto, com população de graduandos em medicina e enfermagem, enfermeiros intensivistas e também de docentes (LONGUINIERE et al, 2016; REIS et al, 2013; FREIRE et al., 2016).

A incompreensão sobre o que é a ME também pode ser um dos motivos das falhas na comunicação entre o profissional e o familiar, uma vez que essa carência de informações pode resultar em mensagens incorretas e até mesmo na insegurança do profissional, observada pelo familiar. A busca contínua de conhecimento, por parte dos profissionais da saúde que atuam nos processos de doação e transplante de órgãos, é essencial uma vez que a família mostra-se bastante atenta às informações recebidas e formaliza questionamentos relacionados ao assunto.

Um estudo desenvolvido entre 2009 e 2010, no Hospital Universitário da Universidade Federal de São Paulo, apontou que 26\% das recusas familiares para a doação de órgãos sendo o motivo a falta de competência técnica dos profissionais que realizaram as entrevistas e, em contrapartida, esses profissionais mencionam a falta de cursos, discussões de casos e trocas de experiências para minimizar os erros e aprimorar o aprendizado (PESSOA, SCHIRMER, ROZA, 2013).

Frente a essa problemática indicada pelos familiares, relacionada à falta de competência dos profissionais para abordarem o assunto doação de órgãos, deve-se também considerar a existência de dificuldades expressadas pelos profissionais da saúde para a realização de cursos de formação. Diversos motivos são apontados, como: indisponibilidade de carga horária; jornadas de trabalho exaustivas, muitas vezes com responsabilidades em mais de um emprego; falta de tempo para deslocamentos aos grandes centros dos profissionais que trabalham no interior do Estado; limitações financeiras; e dificuldades para conciliar as atividades profissionais com as exigências pessoais e familiares.

Em decorrência das adversidades para a participação dos profissionais em cursos de atualização ou especialização presenciais, considera-se muito importante a inserção do Ensino à Distância $(\mathrm{EaD})$ como educação continuada, formato esse que se mostra como valorosa ferramenta para o ensino, alcançando a população que indica dificuldades para iniciar e continuar os estudos. Esse formato de ensino facilita a adaptação dos discentes que não possuem considerável tempo para estudar, levando em conta o deslocamento até a instituição 
de ensino e a dificuldade de conciliar o emprego, o qual gera remuneração para o sustento (RODRIGUES, 2014).

Com o crescimento do EaD no Brasil, o setor da saúde vislumbrou uma nova possibilidade de oportunizar a educação continuada aos profissionais inseridos nessa área. Isso se deve ao formato de ensino oferecer flexibilidade às necessidades individuais de cada aluno, sendo visto como uma forma de modificar e melhorar a formação dos profissionais da saúde (OLIVEIRA et al., 2013). Como alternativa para sanar esse problema e atender às necessidades de educação para esses profissionais, o desenvolvimento e realização de cursos de $\mathrm{EaD}$ pode se tornar uma ótima ferramenta de ensino para os profissionais que necessitam desse formato de educação flexível e eficaz.

O estudo teve como objetivo desenvolver e aplicar um curso de ensino à distância sobre doação e transplante de órgãos, visando qualificar e capacitar médicos e enfermeiros de Unidades de Terapia Intensivas e Emergências do Rio Grande do Sul (RS).

\section{Metodologia}

Trata-se de uma pesquisa de intervenção educativa com método misto, também conhecido como múltiplo. Este método, tem sido utilizado de forma crescente em diversas áreas do conhecimento, através da união de duas abordagens, quantitativa e qualitativa, implementados de forma concomitante ou sequencialmente. O pesquisador produz sua investigação considerando que a utilização de diversos tipos de dados (instrumentos de coleta) irá garantir uma melhor compreensão do problema (FARRA, LOPES, 2013).

O curso foi ofertado por uma Universidade Federal em parceria com a Central de Transplantes Estadual do Rio Grande do Sul (RS), responsável por todas as notificações de ME, captação dos órgãos e sua distribuição para os Centros Transplantadores.

O ambiente de apoio escolhido para o desenvolvimento da maior parte do projeto de ensino e educação foi a Plataforma Moodle (Modular Object-Oriented Dynamic Learning Environment), disponibilizada pela própria Universidade. Esse ambiente permite a interação, participação e troca de experiências entre os alunos, visando a construção do conhecimento através da produção e gerenciamento de atividades educacionais, utilizando a internet e/ou em redes locais (PRADO, VAZ, ALMEIDA, 2011). O uso de Ambientes Virtuais de Aprendizagem (AVA) é considerado por muitos, como uma importante ferramenta pedagógica para ser usada nos diversos níveis de ensino, como graduação, pós-graduação e 
capacitação de profissionais da saúde (PRADO, VAZ, ALMEIDA, 2011). Além desse, realizaram-se dois encontros presenciais em salas de aula na Universidade, no ínicio e no final do curso.

Foram convidados médicos e enfermeiros de hospitais do Estado do RS, que atuavam em UTI e/ou Emergência, por entender que essas áreas contemplam os profissionais que estão diretamente envolvidos na identificação, diagnóstico de ME, manutenção do potencial doador, bem como na notificação dos casos á Central Estadual de Transplante de Órgãos e Tecidos. Foram enviadas cartas-convite aos responsáveis administrativos de dez instituições de saúde. Nas situações que não houve retorno, o contato ocorreu com os responsáveis médicos e de enfermagem das UTI desses locais. Nos casos em que, mesmo após esse segundo contato, não foi obtida resposta, a vaga foi remanejada para outro hospital, a fim de oportunizar a outros profissionais que estivessem interessados. Como em algumas instituições os médicos não tiveram disponibilidade para participar do curso, foram indicados enfermeiros. Para participar da pesquisa os sujeitos deveriam ter como pré-requisito: ser graduado há pelo menos dois anos, atuarem em UTI ou Emergência e aceitar o termo de participação no estudo, com a carta de indicação de sua supervisão. Os pré-requisitos para a inscrição no curso não foram rígidos permitindo a participação de profissionais que tinham a expectativa de, em breve, iniciar suas atividades na Comissão Intra-Hospitalar de Doação de Órgãos e Tecidos para Transplantes (CIHDOTT) ou Organização de Procura de Órgãos (OPO). Foram disponibilizadas 40 vagas e 30 foram preenchidas.

O curso com carga horária total de $20 \mathrm{~h}$, foi semipresencial, por ter duas aulas presenciais (8 horas) e oito à distância (12 horas). A ausência de alguns inscritos nas aulas presenciais acarretou na queda da nota final, uma vez que proporcionava nota referente a uma atividade avaliativa.

Foram utilizadas algumas ferramentas para conhecer o perfil dos participantes, observar o conhecimento prévio referente ao tema abordado no curso, avaliar o conhecimento adquirido antes e após cada aula, bem como avaliar como foi o curso (Ilustração 1). 
Res., Soc. Dev. 2019; 8(1):e581510

ISSN 2525-3409 | DOI: http://dx.doi.org/10.33448/rsd-v8i1.510

Ilustração 1: Etapas e atividades desenvolvidas durante o curso.

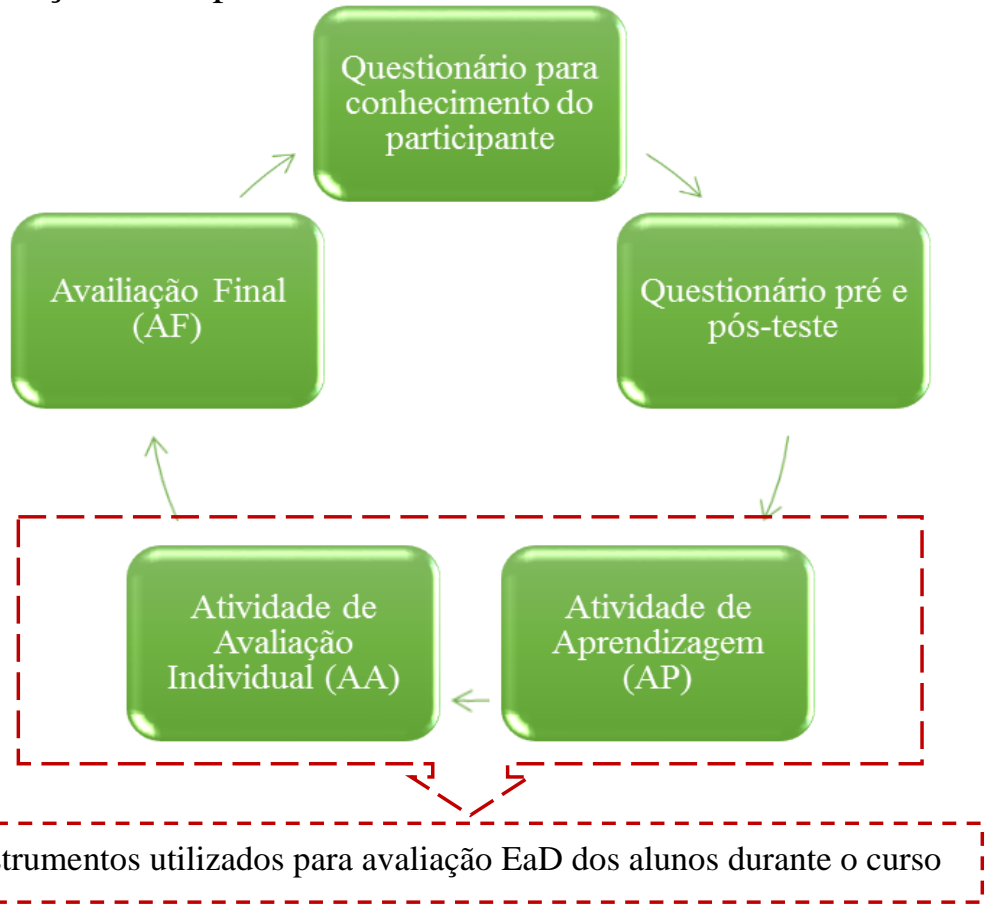

Fonte: Dados da pesquisadora (2017).

Após a conclusão dos estudos de cada aula, os discentes realizaram atividades de avaliação individual e de aprendizagem, as quais foram atribuídas notas.

A coleta de dados ocorreu de forma quantitativa, por meio de aplicação de questionário pré e pós-tese, aplicação da Atividade de Aprendizagem e da Atividade de Avaliação Individual. Ambas com análises descritivas e percentuais simples. A contribuição qualitativa se deu por meio da realização da atividade de avaliação final da aula denominada de X, com a aplicação de grupo focal com análise das falas dos alunos sobre o significado dos trabalhos apresentados.

\section{Resultados e Discussão}

O perfil dos 30 alunos inscritos foi composto por $87 \%$ dos profissionais do sexo feminino e $80 \%$ enfermeiros. De alguma forma, os profissionais da enfermagem se mostraram mais disponíveis para a realização do curso quando comparados aos médicos, fazendo com que não houvesse um número semelhante de alunos entre as duas categorias profissionais. $\mathrm{O}$ resultado evidenciado vai ao encontro de dados disponibilizados pelo Conselho Federal de Enfermagem (COFEN), que mostra dados nacionais sobre a distribuição dos enfermeiros quanto ao sexo, sendo $85,1 \%$ feminino e 14,4\% masculino (FIOCRUZ, COFEN, 2013). 
O curso inscreveu 30 profissionais, com uma parcela que não atendia completamente aos critérios de inclusão, tendo como motivo, a pretensão dos interessados em atuar na área de doação e transplantes. Portanto, em relação ao tempo de formação exigido, apenas um dos 30 inscritos tinham menos de dois anos de conclusão do curso de graduação. Apresenta-se na Ilustração 2 os campos de atuação dos inscritos, nas instituições de saúde.

Ilustração 2: Distribuição dos alunos inscritos com relação à área de atuação.

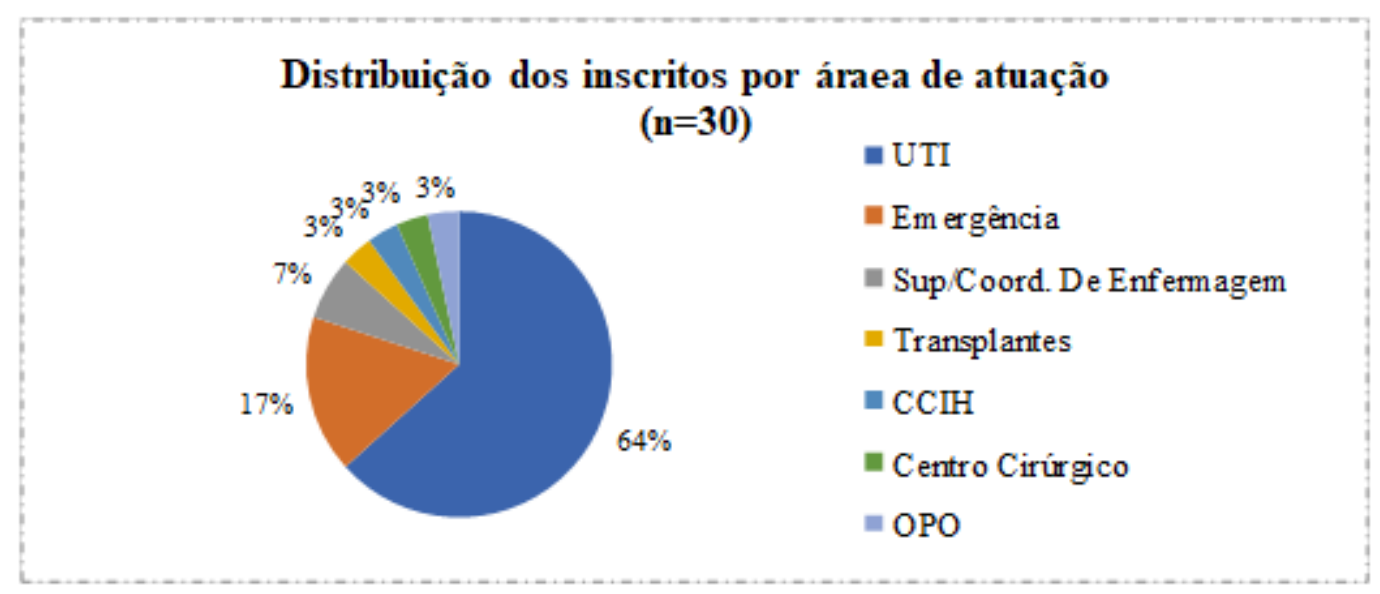

Fonte: Dados da pesquisadora (2017).

Esse panorama distinto de locais de atuação dos profissionais considera-se positivo, pois proporciona ensino aos profissionais da saúde àqueles que podem se tornar multiplicadores do tema e atuar de outras formas no acolhimento e auxílio às famílias.

\section{AULAS PRESENCIAIS - primeira (I) e última (X)}

Os encontros presenciais ocorreram no primeiro (aula I) e último (aula X) dia do curso, com diferentes atividades, conforme Ilustração 3.

Ilustração 3: Distribuição das atividades nas aulas I e X e número de alunos em cada

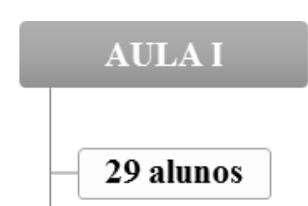

Se dividiu em 5 momento:

- Apresentação do Moodle aos alunos;

- Apresentação dos alunos;

- Entrega de materiais do curso;

- Perguntas sobre o curso;

- Roda de conversas com profíssionais da área de doação e transplantes.

Fonte: Dados da pesquisadora (2017). encontro.

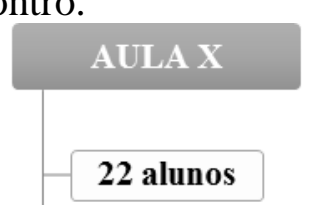

Se dividiu em 5 momento:

- Relatos de experiência da doação;

- Pós-teste;

- Questionário para avaliação do curso;

- Atividade de avaliação final do curso. 
Na primeira aula do curso, presencial, compareceram 29 alunos, dos 30 inscritos. A adesão dos alunos na aula de número um tinha como base os 30 alunos inscritos. Como um aluno não compareceu, as demais aulas tiveram como base os 29 participantes, uma vez que havia sido comunicado que não era permitido faltar na primeira aula.

Nesse primeiro encontro foi aplicado o questionário para conhecimento dos participantes, e constatou-se que 55\% não teriam disponibilidade de realizar o curso caso fosse em formato presencial. A ilustração 4 apresenta os motivos apontados pelos 16 alunos que informaram não ter disponibilidade de participar, caso o curso fosse presencial.

Ilustração 4: Principais motivos para a não realização do curso no formato presencial.

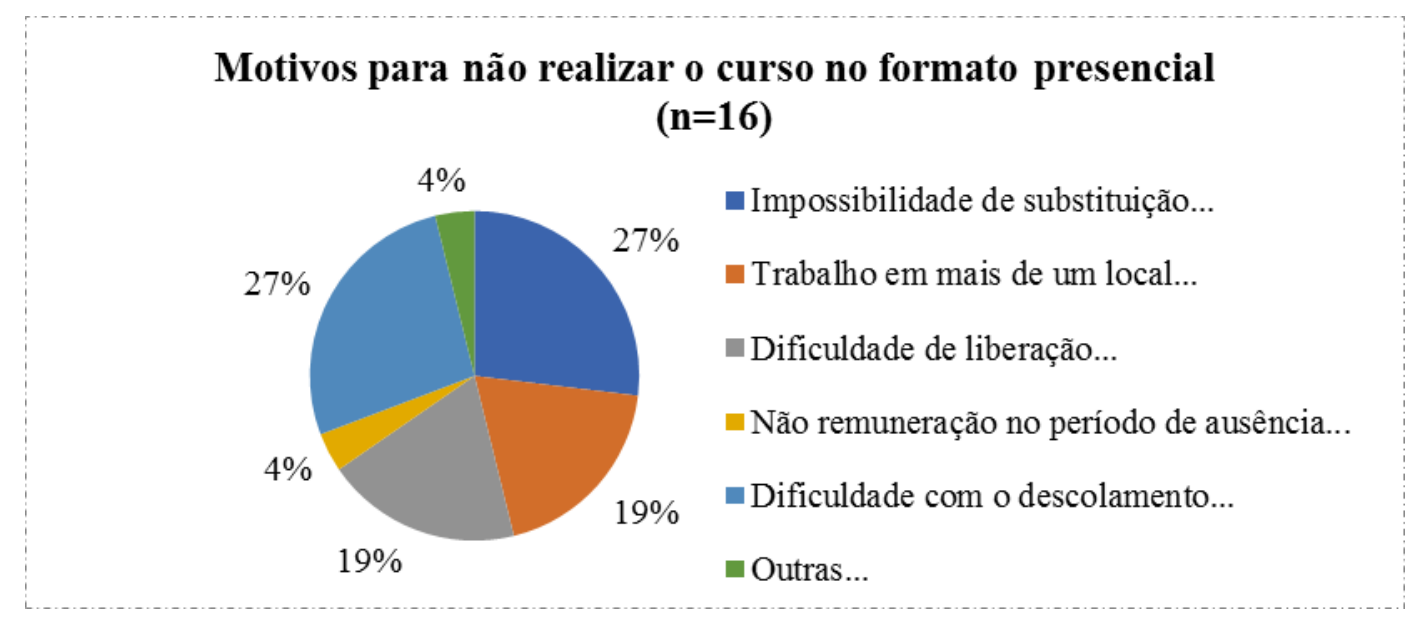

Fonte: Dados da pesquisadora (2017).

Os resultados apresentam alguns pontos semelhantes a outra pesquisa desenvolvida com profissionais da enfermagem, que evidenciou como principais motivos para o não aprimoramento: a falta de condições financeiras $24,6 \%$, falta de apoio institucional $11,2 \%$, falta de tempo, motivação e estímulo 13,9\%, dificuldade de parar de trabalhar 10,2\%, falta de programas de treinamentos no trabalho 8,4\% e a distância 6,0\% (FIOCRUZ, COFEN, 2013). O Censo 2016-2017 da Associação Brasileira de Ensino à Distância (ABED), apontou que os alunos que optaram pelo EaD não teriam outra forma de estudar pela falta de tempo disponível (ABED, 2016).

Essas dificuldades mostram a importância da realização de cursos no formato de $\mathrm{EaD}$, visando contemplar esses profissionais e suprir a necessidade de ensino e aprimoramento, principalmente para assuntos mais específicos, como a doação de órgãos e transplantes, que ocorrem em áreas específicas das instituições hospitalares. 
Na última aula participaram 22 alunos, dos 29 que participaram da primeira aula, portanto $78,5 \%$ de adesão até o final do curso. Os discentes sentaram-se em classes que estavam disponíveis em formato de círculo, propiciando que todos pudessem enxergar aos colegas, tornando o ambiente convidativo a participação e contribuição de todos que ali estavam presentes.

Após o preenchimento do pós-teste, sem questionamentos ou dúvidas por parte dos alunos, foi preenchido o questionário de avaliação do curso, com sete questões relacionadas à avaliação do curso e ao modelo, para conhecer como este foi recebido e realizado pelos discentes, podendo assim mostrar pontos a serem melhorados e fortalecidos nas edições seguintes. As respostas estão representadas na Ilustração 5.

Ilustração 5: Respostas dos alunos ao questionário de avaliação do curso

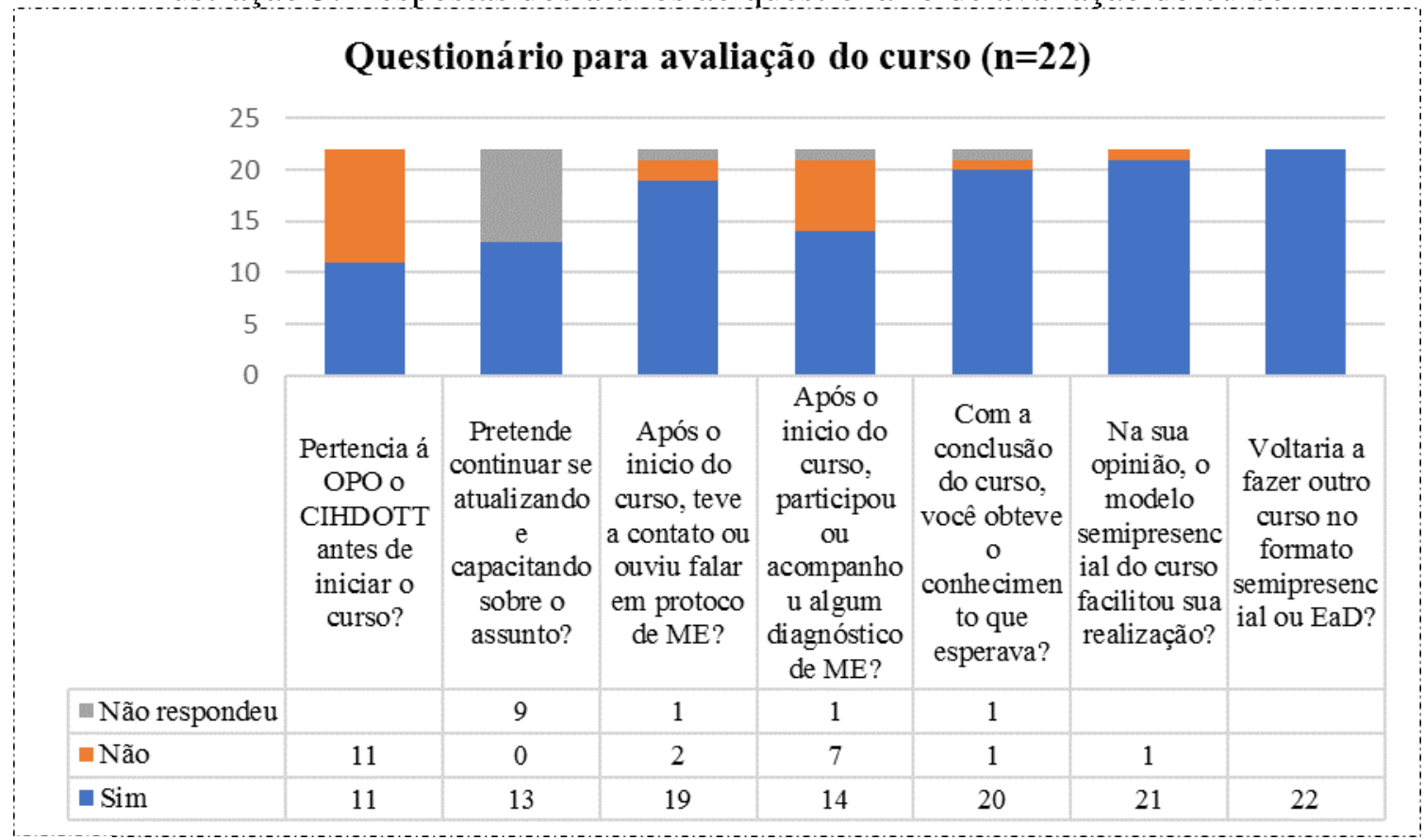

Fonte: Dados da pesquisadora (2017).

Sobre o comentário inserido na pergunta 5 do questionário, um aluno respondeu o motivo porque, após a conclusão do curso não obteve o conhecimento esperado: “Acho que é preciso estudar muito mais sobre o tema. O curso foi excelente, esclarecendo muitas dúvidas e norteando as buscas".

Para 95\% dos alunos que preencheram o questionário, o modelo de EaD facilitou a conclusão do curso, informação essa que infere ser esse formato de ensino como ferramenta indispensável à continuação dos estudos. Esses dados vão ao encontro de resultado obtido em pesquisa realizada com profissionais da enfermagem, a qual apontou que no RS, 37,1\% 
utilizam a internet como ferramenta para o aprimoramento profissional (FIOCRUZ, COFEN, 2013; ABED, 2016).

O mesmo questionário trouxe perguntas referentes à satisfação dos alunos com o curso, apresentando a seguinte amostragem (Ilustração 6):

Ilustração 6: Todos os itens avaliados quanto o grau de satisfação dos alunos com o curso

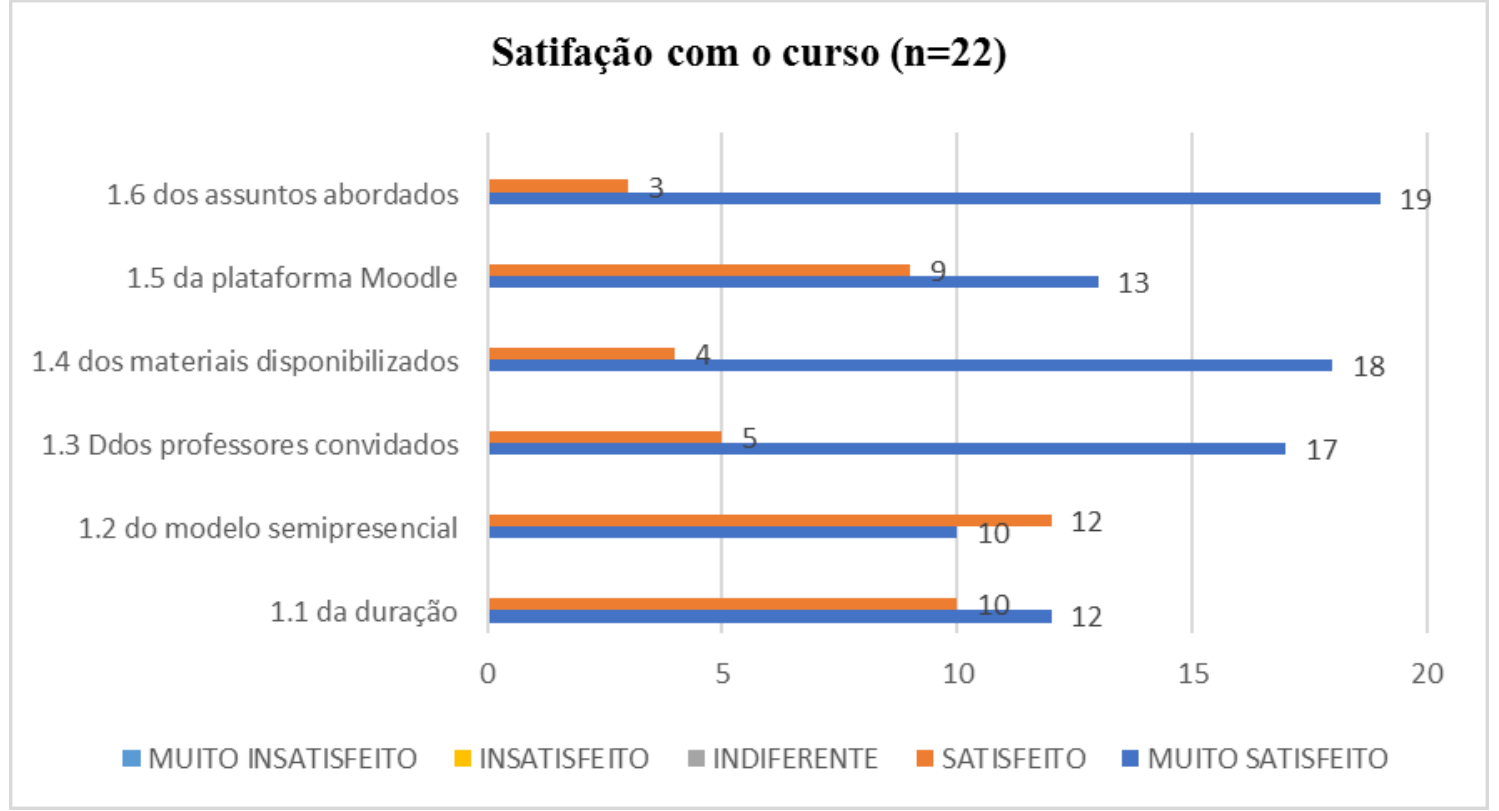

Fonte: Dados da pesquisadora (2017).

De uma forma geral a satisfação dos alunos com o curso, foi de satisfatória a muito satisfatória, preponderando o grau máximo de satisfação.

Após o preenchimento do questionário para avaliação do curso, os alunos foram convidados à realização da atividade de avaliação final, que contou com a participação de 22 alunos, divididos em cinco grupos. Cada grupo recebeu folhas grandes de papel pardo, contendo em cada folha as frases "O que é vida?" e "O que é morte?". Diversos materiais escolares (EVA colorido, cola, tesoura, revista, giz de cera, durex e outros) foram disponibilizados, sendo orientados e estimulados a explicitar o significado das frases para o grupo.

As conversas gravadas foram transcritas na íntegra. A análise dos dados ocorreu pela ordenação dos dados (transcrição das gravações, releitura do material e organização dos relatos), classificação dos dados (leitura dos textos e elaboração das categorias) e análise final (estabelecimento de inter-relações entre os dados e os referenciais teóricos da pesquisa). 
O diálogo entre os participantes da pesquisa, compuseram alguns pontos importantes de reflexão sobre essas duas perguntas instigadas ao início da última aula. As frases referidas pelos alunos compuseram os tópicos apresentados na Ilustração 7.

Ilustração 7: Tópicos abordados pelos grupos focais.

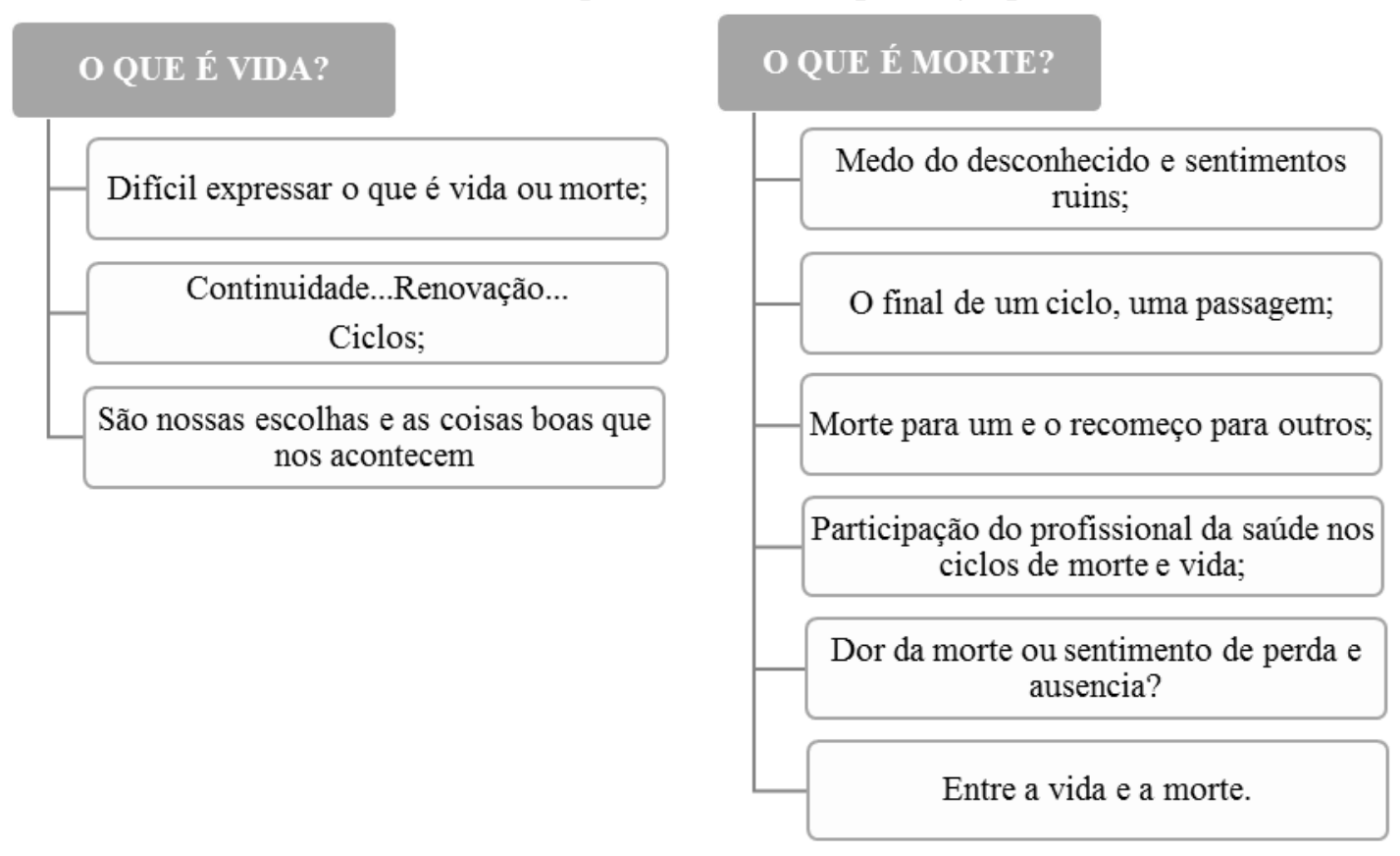

Fonte: Dados da pesquisadora (2017).

Alguns grupos expressaram dificuldade de descrever em imagens o que era sentido, remetendo os participantes a necessidade de dialogar e refletir sobre os conceitos pessoais do que seria "a vida e a morte", e como o assunto ainda é pouco discutido entre a população. Perceberam que, quando trouxeram os conceitos do que era "a vida e morte", em vários momentos essas duas situações se encontram. Mesmo quando queriam falar de vida, em certa ocasião o tema morte se encaixava, e assim vice-versa.

Trouxeram a vida como sendo uma oportunidade de continuação de algo, um ciclo, ou um momento em que é possível a renovação do ser humano. Apontaram a importância de aproveitar os momentos felizes e que, aos poucos, todos estão morrendo, como parte da natureza do ser humano.

A morte tornou-se um assunto de difícil diálogo e compreensão. Foram expressadas através das imagens, pela maioria dos grupos, com cores escuras, imagens de frio, tristeza, lágrimas e outras relacionando-a como algo desconhecido, a qual ninguém sabe como e nem quando acontecerá. Esse medo da morte se faz muito presente em nossa sociedade, onde se estabeleceu esse conceito de que morrer é algo ruim, traumatizante e que nunca deverá ser 
pensado por alguém próximo. Um dos grupos apontou o medo da morte como sendo algo cultural e estruturado pela comunidade, onde quem nasce vai estabelecendo seus conceitos e preconceitos com base no que vivencia e lhe é socialmente ensinado

A morte ainda é um tema que gera emoções profundas e, muitas vezes, perturbadoras, as quais a grande maioria das pessoas tende a negar, porém, é um fenômeno inarredável, algo que pode ocorrer a qualquer momento, para qualquer um de nós. Ocorre que a maioria dos indivíduos está despreparada para tal acontecimento (RINPOCHE, 2008).

Atualmente, o discurso sobre a morte é tido como responsável por atrai-la, ou até mesmo expressado por aquele não gosta do doente ou que deseja a sua morte. Os grupos apontaram a morte como parte de uma passagem, que será vivenciada por todos. O luto é uma situação essencial, como parte do processo de perda para aqueles que continuam vivendo, sendo muito importante libertar-se dos possíveis sentimentos de culpa.

Alguns alunos relacionaram a pergunta do que é a morte com o assunto estudado no curso, ligando a vida, a morte e a doação de órgãos como sendo um recomeço da vida para quem recebe um transplante.

Os grupos trouxeram a importância do preparo para lidar com a morte. Durante a formação acadêmica dos profissionais da saúde, estes salientaram que a orientação profissional é embasada apenas na manutenção da vida a qalquer custo, ocasionando tristeza e despreparo quando esses objetivos não são alcançados.

Dessa forma, os profissionais da saúde acabam se decepcionando consigo mesmos ao não conseguirem atender às necessidades do paciente gravemente enfermo que morre. Por isso, o profissional deve entender que suas atribuições estão relacionadas a sua capacidade de acompanhar os pacientes doentes, proporcionando melhor acolhimento e cuidado durante o período que ficará internado, podendo estender-se até o momento da morte (KOVÁCS, 2003).

O prolongar de investimentos desnecessários, mesmo quando o óbito será inevitável, gerou diversos discursos como: até quando se deve manter por meios artificiais aquele corpo? É ético com o paciente e com a família?

A medicalização da morte ou a morte clínica fez com que houvesse alterações no percurso para a morte, onde os doentes passaram a ser levados aos hospitais para morrer, diferentemente do que acontecia anteriormente, quando os enfermos faleciam em suas 
próprias casas. A morte em algumas ocasiões tornou-se um acontecimento técnico, onde o médico determina quando continuar ou interromper o tratamento, fazendo com que nem a família nem o indivíduo sejam responsáveis pela sua própria morte, proporcionando novos significados referentes à finitude dos indivíduos (OLIVEIRA et al., 2003; CORREA, HASHIMOTO, 2012). Para Junges et al. (2010, p. 275): “o fim da vida passa a ser um acidente não admissível e, todos os meios devem ser utilizados para, ao menos, retardá-lo".

Algumas literaturas já apontam a relevância do indivíduo trabalhar as perdas relacionadas à morte, como por exemplo o livro Perdas Necessárias, de Judith Viorst (2011) que traz a importância das experiências de perda para o desenvolvimento emocional das pessoas.

Esta última aula tornou-se um importante momento de reflexão para todos, estimulando-os a refletir e levar esses tópicos para além do curso, para serem trabalhados de forma constante com as vivências e situações cotidianas.

\section{AULA EAD}

Em todas as aulas de EaD foram incluídas na plataforma Moodle algumas atividades e materiais para serem acessados e estudados pelos alunos, tais como (Ilustração 8):

Ilustração 8: Distribuição das atividades nas aulas EaD.

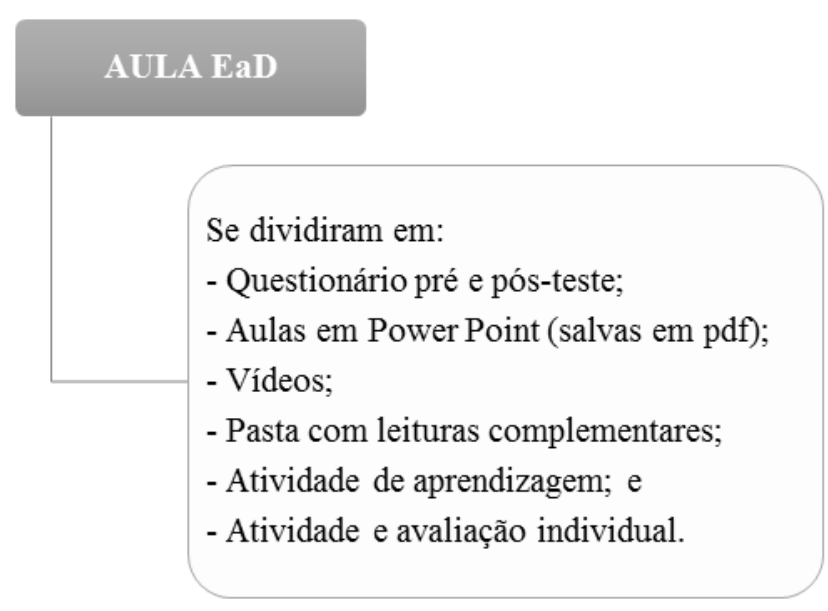

Fonte: Dados da pesquisadora (2017).

\section{Pré e Pós-teste}

Para analisar a média de notas dos alunos que realizaram a atividade pré e pós-teste em cada aula, foi utilizado teste $\mathrm{T}$ de amostras pareadas, que apresentou média de notas mais 
ISSN 2525-3409 | DOI: http://dx.doi.org/10.33448/rsd-v8i1.510

elevadas após o acompanhamento dos estudos por parte dos discentes, quando os questionários pós-teste evidenciaram que os alunos tiveram melhor nota no pós-teste em todas as aulas. Para isso, não foram considerados aqueles que preencheram somente o pré ou o apenas pós teste, apreciando as informações dos discentes que preencheram ambos os questionários em cada aula. Esse é um importante indicador quanto ao conhecimento adquirido pelos alunos, mostrando que as aulas atenderam aos objetivos de proporcionar o conhecimento e discussão acerca do assunto doação de órgãos e transplantes.

Quando analisado quantos fizeram o pré e não fizeram o pós-teste, e vice-versa, foi utilizada a tabulação cruzada de pré e pós-teste, apresentada na Tabela 1.

Tabela 1: Alunos que realizaram pré e pós-teste por aula.

\begin{tabular}{|c|l|l|l|l|l|l|}
\hline & $\begin{array}{c}\text { n } \\
\text { PRT }\end{array}$ & \multicolumn{2}{|c|}{$\begin{array}{c}\text { Fez pré-teste e não } \\
\text { fez pós-teste }\end{array}$} & $\begin{array}{c}\text { n } \\
\text { PST }\end{array}$ & \multicolumn{2}{c|}{$\begin{array}{c}\text { Fez pós-teste e não } \\
\text { fez pré-teste }\end{array}$} \\
\hline & & $\mathrm{n}$ & $\%$ & & $\mathrm{n}$ & $\%$ \\
\hline Aula I e X & 28 & 7 & $25,0 \%$ & 22 & 1 & $4,5 \%$ \\
\hline Aula II & 8 & 1 & $12,5 \%$ & 25 & 18 & $72 \%$ \\
\hline Aula III & 14 & 0 & $0,0 \%$ & 25 & 11 & $44,0 \%$ \\
\hline Aula IV & 22 & 3 & $13,6 \%$ & 25 & 6 & $24,0 \%$ \\
\hline Aula V & 19 & 0 & $0,0 \%$ & 27 & 8 & $29,6 \%$ \\
\hline Aula VI & 24 & 1 & $4,2 \%$ & 25 & 2 & $8,0 \%$ \\
\hline Aula VII & 18 & 1 & $5,6 \%$ & 22 & 5 & $22,7 \%$ \\
\hline Aula VIII & 19 & 1 & $5,3 \%$ & 23 & 5 & $21,7 \%$ \\
\hline Aula IV & 20 & 1 & $5,0 \%$ & 22 & 3 & $13,6 \%$ \\
\hline Legenda: $P R T$ & $=$ Pré-teste; $P S T=$ Pós-teste & \\
\hline
\end{tabular}

Fonte: Dados da pesquisadora (2017).

Nessa análise foi possível observar que a grande maioria dos alunos fez o questionário pós-teste sem ter realizado o pré-teste, não sendo possível analisar a média de notas nessa atividade desses alunos em cada aula. Isso talvez seja o reflexo da condição exposta para essas atividades, que preconizava que o questionário pré-teste fosse preenchido e enviado em até 2 dias após o início de cada aula.

\section{$\underline{\text { Atividade de Aprendizagem e de Avaliação Individual }}$}

Quando avaliadas as Atividades de Aprendizagem (AP) e as Atividades de Avaliação Individual (AA) realizadas nas aulas $\mathrm{EaD}$, todos os participantes atingiram valores na média acima da preconizada pelo curso. Foram analisadas também a relação entre as notas das AP e AA com a idade dos alunos, utilizando o teste de correlação de Pearson. Nos resultados não se observou correlação significativa entre os pontos analisados, exceto na atividade de aprendizagem da aula VI (temática da manutenção do doador elegível), onde os alunos mais 
jovens obtiveram as maiores notas $(\mathrm{r}=-551$; $\mathrm{p}$-valor=0,012). Observou-se também que o tempo de formação não influenciou no desempenho dos alunos.

Quando analisada a relação entre formação complementar e o desempenho dos alunos, através do teste t de amostras independentes, não houve significância, devendo-se ao pequeno número de alunos que não tinham formação complementar. $\mathrm{O}$ pequeno número de profissionais sem formação complementar, apresenta embasamento quando relacionada com resultados de pesquisa realizada com enfermeiros no RS, mostrando que 80,3\% dos profissionais dessa área tem algum tipo de especialização posterior à graduação (FIOCRUZ, COFEN, 2013).

Quando analisadas as notas das atividades avaliativas com a atuação dos alunos em OPOs/CIHDOTTs e aqueles que não atuam na área, por meio do teste $\mathrm{t}$ para amostras independentes, não houve significância, exceto a atividade de aprendizagem da aula sobre Captação e Transplante de coração, pulmão, fígado, rins e pâncreas, que apresentou melhores notas para aqueles que não atuavam nas OPOs e CIHDOTTs.

\section{Conclusão}

O curso de formação em Doação e Transplantes disponibilizado aos profissionais da saúde (médicos e enfermeiros) teve boa avaliação por parte dos discentes, que se mostraram muito satisfeitos com os assuntos abordados e o formato do curso. Todos os alunos indicaram que voltariam a fazer outros cursos nesse formato de ensino e que esse modelo facilitou a conclusão das atividades.

A impossibilidade de substituição no serviço e o deslocamento para a realização do curso no formato presencial, foram os principais motivos para a participação dos alunos, evidenciando que o EaD se mostra como uma oportunidade de educação nessas situações. Esse resultado induz à reflexão sobre a importância de serem concedidas licenças pelas chefias, para que os profissionais da saúde se capacitem e atualizem.

O curso de formação profissional foi importante pois extendeu a educação também aos profissionais que estão distantes dos grandes centros, responsáveis pelas capacitações especificas de determinados temas. O EaD deve ser empregado a fim de possibilitar o aprendizado ao aluno, sanando dúvidas, capacitando o profissional e instigando-o para novos pensamentos que irão interferir nas suas condutas. 
Res., Soc. Dev. 2019; 8(1):e581510

ISSN 2525-3409 | DOI: http://dx.doi.org/10.33448/rsd-v8i1.510

A recente atualização do protocolo para Diagnóstico de Morte Encefálica explicita ainda mais a importância da educação para esses profissionais de saúde, que devem conhecer essas mudanças para gozar de segurança na realização do diagnóstico. Incrementos devem ser aplicados no curso em formato EaD disponibilizando-o para todos os profissioanis da saúde interessados. Posteriormente as pesquisadoras intencionam conhecer a atuação desses profissionais, participantes do curso, nas áreas da doação e transplante, bem como analisar a necessidade de educação continuada.

\section{Referências}

ABED - Associação Brasileira de Ensino a Distância. Censo 2016. Disponível em: http://abed.org.br/censoead2016/Censo_EAD_2016_portugues.pdf. Acessado em: $10 \mathrm{de}$ agosto de 2018.

CORREA, M. R.; HASHIMOTO, F. Finitude, envelhecimento e subjetividade. Revista Temática Kairós Gerontologia,15(4), "Finitude/Morte \& Ve- lhice", p. 85-99. Online ISSN 2176-901X. Print ISSN 1516-2567. São Paulo (SP), Brasil: FACHS/NEPE/PEPGG/PUC-SP.

FARRA, R. A. D.; LOPES, P. T. C. Métodos mistos de pesquisa em educação: Pressupostos teóricos. Nuances: estudos sobre Educação. Presidente Prudente-SP, v. 24, n. 3, p. 67-80, set./dez. 2013.

\section{FIOCRUZ, COFEN. Pesquisa Perfil de Enfermagem no Brasil, 2013.}

FREIRE, I. L. S. et al. Aceitação e conhecimento de docentes de enfermagem sobre a doação de órgãos e tecidos. Rev enferm UERJ, Rio de Janeiro, 2016; 24(1):e15561.

JUNGES, J. R. et al. Reflexões legais e éticas sobre o final da vida: uma discussão sobre a ortotanásia. Revista Bioética 2010; 18 (2): 275 - 88.

KAZLEY, A. S. et al. Barriers facing patients referred for kidney transplant cause loss to follow-up. Kidney Int. 2012-November; 82(9): 1018-1023. doi:10.1038/ki.2012.255.

KOVÁCS, M. J. Educação para a morte: temas e reflexões. São Paulo: Casa do Psicólogo. Facesp, 2003.

LONGUINIERE, A. C. F. de la. et al. Conhecimento de enfermeiros intensivistas acerca do processo de diagnóstico da morte encefálica. Rev Rene. 2016 set-out; 17(5):691-8.

OLIVEIRA, A. E. F. de. et al. Educação a Distância e Formação Continuada: em Busca de Progressos para a Saúde. Revista brasileira de educação médica. 37 (4): 578 - 583; 2013.

OLIVEIRA, H. B. de. et al. Ética e eutanásia. Simpósio Medicina e Direito. J Vasc Br 2003, Vol. 2, No3.

PEREIRA, W. A.; FERNANDES, R. C.; SOLER, W. de V. Diretrizes básicas para captação e retirada de múltiplos órgãos e tecidos da Associação Brasileira de Transplante de Órgãos. São Paulo: ABTO - Associação Brasileira de Transplante de Órgãos, 2009. 
PESSOA, J. L. E.; SCHIRMER, J.; ROZA, B. de A. Avaliação das causas de recusa familiar a doação de órgãos e tecidos. Acta Paul Enferm. 2013; 26(4):323-30.

PRADO, C.; VAZ, D. R.; ALMEIDA, D. M. de. Teoria da aprendizagem Significativa: elaboração e avaliação de aula virtual na plataforma moodle. Rev Bras Enferm, Brasília 2011 nov-dez; 64(6): 1114-21.

RBT - Registro Brasileiro de Transplantes. Associação Brasileira de Transplante de Órgãos (ABTO). Ano XXIII No 3. 2017.

REIS, F. P dos. et al. Morte encefálica e transplante de órgãos e tecidos: o entendimento dos alunos do curso de Medicina. Rev Bras Ter Intensiva. 2013;25(4):279-283.

RINPOCHE, C. T. Vida e morte no budismo tibetano. Três Coroas: Makara, 2008. 92p. : il. RODRIGUES, E. F. de S. Educação a distância: uma experiência exitosa. Trabalho de Conclusão de Curso apresentado ao Curso de Especialização em Gestão Pública da Universidade da Integração Internacional da Lusofonia Afro-Brasileira como parte dos requisitos para a obtenção do título de Especialista. Ano 2014. Disponível em:

http://repositorio.unilab.edu.br:8080/jspui/bitstream/123456789/318/1/Elana\%20Fl\%C3\%A1via\%20d e\%20Sousa\%20Rodrigues.pdf. Acessado em 12/04/2018.

SCHEIN, A. E. et al. Avaliação do Conhecimento de Intensivistas sobre Morte Encefálica. Revista Brasileira de Terapia Intensiva. Vol. 20 N $^{\circ}$ 2, Abril/Junho, 2008.

SILVA, F. A. A. da. et al. Morte encefálica e manutenção de órgãos: conhecimento dos profissionais intensivistas. Rev enferm UFPE on line., Recife, 12(1):51-8, jan., 2018. 